\title{
Recurrent Intracranial Hemorrhagic Episodes in Hepatopulmonary Syndrome
}

\author{
Hiroshi Smro, Haruka Sasaki, Katsuya Nishimaru and Makoto OkUmura
}

\begin{abstract}
A 57-year-old woman with hepatopulmonary syndrome was treated for eight years. Severe hypoxemia continued and her erythrocytosis was slowly progressive. Two episodes of intracranial hemorrhagic attack had occurred during the follow-up period and the patient died due to multiple organ failure after the second intracranial hemorrhage. Her autopsy findings confirmed not only established liver cirrhosis associated with intracranial hemorrhage but also the marked dilatation of pulmonary capillaries in both lungs. These findings suggest that secondary erythrocytosis in hepatopulmonary syndrome can be contributed to fatal intracranial vascular accidents. The containment of erythrocytosis should be considered in these patients. (Internal Medicine 31: 786-790, 1992)
\end{abstract}

Key words: liver cirrhosis, hypoxemia, erythrocytosis, cerebral hemorrhage

\section{Introduction}

In some patients with liver cirrhosis, moderate to severe hypoxemia is a complication (1). Abnormal pulmonary vascular channels, such as dilated alveolar capillaries and small arteriovenous communications, is thought to be the major cause of severe hypoxemia in these patients $(2,3)$. Recently, the term "hepatopulmonary syndrome" has been advocated for these pathophysiologic conditions $(3-5)$. Secondary erythrocytosis has also been noted in many of these patients $(6,7)$. We report here a fatal case with hepatopulmonary syndrome associated with marked erythrocytosis. We discuss the management of these conditions.

\section{Case Report}

A 57-year-old woman was referred to our hospital on September 2, 1982 for evaluation of liver dysfunction and cyanosis. She had a history of blood transfusion 11 years previously due to the oophorectomy. She had no history of tobacco, alcohol abuse, or hypertension. On admission, marked cyanosis of the lips and nail beds, and clubbing of the fingers were present. Many vascular spiders were also noted in the anterior chest wall. The liver was not palpable and spleen was palpable $3 \mathrm{~cm}$ below the left costal margin. No ascites was exhibited and the remainder of the examination was negative.
Blood pressure was $110 / 72 \mathrm{mmHg}$.

Laboratory data were as follows: erythrocyte count $5.9 \times 10^{12} / 1$; hemoglobin $197 \mathrm{~g} / 1$; leukocyte count $2.9 \times 10^{9} / 1$; platelet count $66 \times 10^{9} / 1$; serum bilirubin $27 \mu \mathrm{mol} / \mathrm{l}$; aspartate aminotransferase $1.2 \mu \mathrm{kat} / \mathrm{l}$; alanine aminotransferase $0.6 \mu \mathrm{kat} / \mathrm{l}$; lactate dehydrogenase $7.8 \mu \mathrm{kat} / \mathrm{L}$, alkaline phosphatase $2.2 \mu \mathrm{kat} / \mathrm{l}$, $\gamma$-glutamyltransferase $1.7 \mu \mathrm{kat} / \mathrm{l}$, thymol turbidity test 11.7 , prothrombin time $12.6 \mathrm{~s}$ with control $11.9 \mathrm{~s}$, 15 -minute retention rate of indocyanine green $49 \%$, albumin $27 \mathrm{~g} / \mathrm{l}$, and globulin $35 \mathrm{~g} / 1$. Serum hepatitis B surface antigen was negative and antibody to hepatitis $C$ virus was positive. Abdominal ultrasound and computed tomography revealed nodular liver and no evidence of liver tumor. Liver biopsy specimen disclosed established liver cirrhosis.

Arterial blood gas analysis revealed arterial oxygen tension $44 \mathrm{mmHg}$, arterial carbon-dioxide tension $37 \mathrm{mmHg}$, oxygen saturation $81 \%$, and alveolar-arterial oxygen difference $69 \mathrm{mmHg}$. A chest roentgenogram showed an increased vascular marking prominent in the lower zone of the lungs. The electrocardiogram, spirogram, closing volume, and flow volume curve were normal. However, the diffusion capacity, as evaluated by the single breath method, was moderately disturbed $(6.8 \mathrm{ml} / \mathrm{min} / \mathrm{mmHg}, 41 \%$ of predicted value $)$. Echocardiography showed normal intracardiac anatomy, normal wall movement, and no evidence of atrial or

From the First Department of Internal Medicine, School of Medicine, Fukuoka University, Fukuoka

Received for publication October 17, 1991; Accepted for publication February 14, 1992

Reprint requests should be addressed to Dr. Hiroshi Shijo, the First Department of Internal Medicine, Fukuoka University School of Medicine, 7-45-1 Nanakuma, Jonan-ku, Fukuoka 814-01, Japan 


\section{Hepatopulmonary Syndrome}

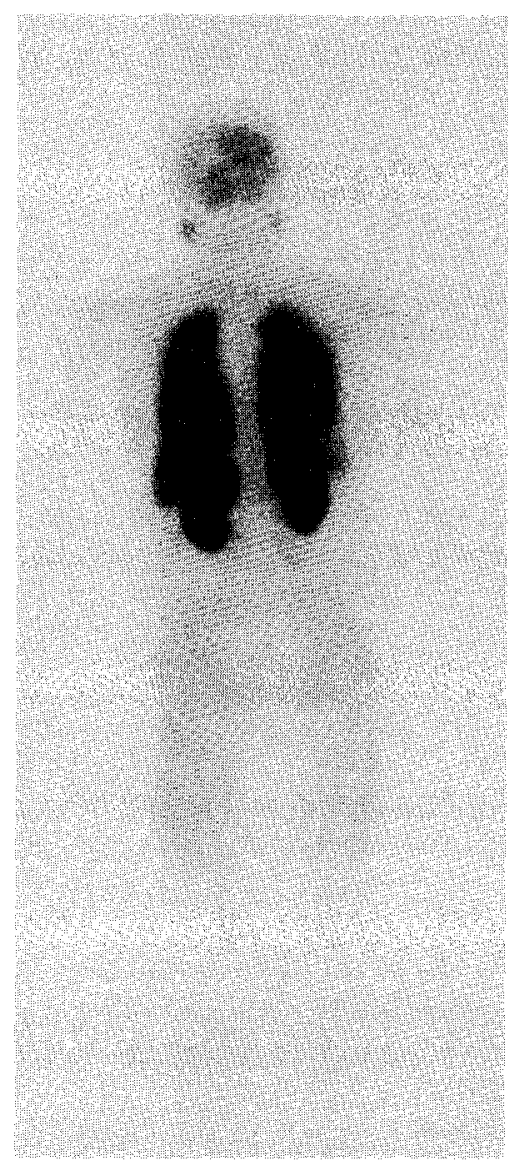

Fig. 1. Whole body imaging of pulmonary perfusion scan by ${ }^{99 \mathrm{~m}} \mathrm{Tc}$-macroaggregated albumin. Uptake is evident in the lungs, spleen, brain, and both kidneys. ventricular septal defects.

The physiological shunt ratio (QS/QT), obtained under the conditions of $100 \%$ oxygen inhalation (8), was $7 \%$. Intravenously injected ${ }^{99 \mathrm{~m}} \mathrm{Tc}$-macroaggregated albumin particles passed through the lungs and whole body imaging revealed a significant uptake not only in both lungs but also in the liver, brain and both kidneys (Fig. 1). The shunt ratio was $69 \%$, as estimated by the quantitative radionuclide method (9). From these findings, a diagnosis of liver cirrhosis associated with hepatopulmonary syndrome was made $(1-7,9)$.

Bone marrow specimens obtained by needle aspiration disclosed normocellular marrow with pronounced erythroid series hyperplasia, and the myeloid/erythroid ratio was 0.58 . The number and size of megakaryocytes was normal. Serum erythropoietin and vitamin $B_{12}$ levels were $38 \mathrm{mIU} / \mathrm{ml}$ (normal: $28-88 \mathrm{mIU} / \mathrm{ml}$ ) and $980 \mathrm{pg} / \mathrm{ml}$ (normal: $450-980 \mathrm{pg} / \mathrm{ml}$ ), respectively. Leukocyte alkaline phosphatase activity was $80 \%$. Routine hemoglobin electrophoresis was normal. The whole blood $\mathrm{P}_{50}$ (the oxygen pressure at which hemoglobin is half-saturated) was $29 \mathrm{mmHg}$ at standard conditions for $\mathrm{pH}$, temperature, $\mathrm{CO}_{2}$ content, and barometric pressure (10). From these findings, complications of polycythemia vera and hemoglobin abnormalities were denied. Her marked erythrocytosis was thought to be a secondary change to compensate for the severe hypoxemia.

After discharge, she was regularly followed up in the outpatient clinic. Her clinical course data is shown in Table 1 . In the subsequent two years, severe hypoxemia continued and erythrocytosis progressed. On October 17, 1984, her serum hemoglobin level reached $239 \mathrm{~g} / \mathrm{l}$. On November 5, 1984, she was readmitted to our hospital because of a severe headache followed by symptoms of right hemiparesis. Left putaminal hemorrhage was found

Table 1. Serial Changes in Blood Gas Analysis and Hematological Findings

\begin{tabular}{|c|c|c|c|c|c|c|c|c|c|c|c|c|c|}
\hline & Date & $\begin{array}{c}1973 \\
\text { Aug. } \\
12\end{array}$ & $\begin{array}{c}1982 \\
\text { Sep. } \\
2\end{array}$ & $\begin{array}{c}1983 \\
\text { Oct. } \\
6\end{array}$ & $\begin{array}{c}1984 \\
\text { Oct. } \\
17\end{array}$ & $\begin{array}{c}\text { Nov. } \\
29\end{array}$ & $\begin{array}{c}1985 \\
\text { Feb. } \\
22\end{array}$ & $\begin{array}{c}\text { Apr. } \\
17\end{array}$ & $\begin{array}{c}1986 \\
\text { Jul. } \\
31\end{array}$ & $\begin{array}{c}1987 \\
\text { Nov. } \\
26\end{array}$ & $\begin{array}{c}1988 \\
\text { Oct. } \\
13\end{array}$ & $\begin{array}{c}1989 \\
\text { Apr. } \\
10\end{array}$ & $\begin{array}{c}1989 \\
\text { Nov. } \\
17\end{array}$ \\
\hline $\mathrm{PaCO}_{2}$ & $(38-42 \mathrm{mmHg})$ & - & 37 & - & 32 & 34 & 33 & 34 & - & - & 33 & - & 41 \\
\hline $\mathrm{SO}_{2}$ & $(>90 \%)$ & - & 81 & - & 85 & 80 & 78 & 85 & - & - & 79 & - & 79 \\
\hline $\mathrm{A}-\mathrm{aDO}_{2}$ & $(<10 \mathrm{mmHg})$ & - & 69 & - & 69 & 74 & 76 & 68 & - & - & 74 & - & 66 \\
\hline ALT & $(0-0.58 \mu \mathrm{kat} / 1)$ & 0.83 & 0.63 & 1.63 & 1.10 & 0.62 & 0.40 & 0.38 & 2.25 & 1.75 & 1.47 & 2.42 & 1.55 \\
\hline Erythrocyte count & $\left(3.5-5.0 \times 10^{12} / I\right)$ & 3.4 & 5.9 & 6.5 & 6.7 & 4.9 & 5.5 & 6.6 & 6.6 & 7.3 & 6.6 & 6.7 & 6.6 \\
\hline Hemoglobin & $(120-150 \mathrm{~g} / 1)$ & 171 & 197 & 210 & 239 & 163 & 181 & 192 & 205 & 226 & 223 & 227 & 227 \\
\hline Leukocyte count & $\left(3.2-9.8 \times 10^{9} / 1\right)$ & 4.5 & 2.9 & 2.9 & 3.1 & 3.8 & 3.5 & 2.7 & 3.2 & 3.2 & 2.4 & 2.3 & 2.1 \\
\hline Platelet count & $\left(130-400 \times 10^{9} / 1\right)$ & 82 & 66 & 54 & 45 & 70 & 74 & 67 & 57 & 45 & 45 & 39 & 37 \\
\hline
\end{tabular}

Left putaminal hemorrhage: 5 Nov. 1984. Total dose of $800 \mathrm{ml}$ of venesection was administered on 9-11 Nov. 1984. Cerebellar hemorrhage: 5 Feb. 1990. Data in parenthesis indicates normal range

$\mathrm{PaO}_{2}$ : arterial oxygen tension, $\mathrm{PaCO}_{2}$ : arterial carbon dioxide tension, $\mathrm{SO}_{2}$ : oxygen saturation, $\mathrm{A}$-aDO $\mathrm{O}_{2}$ : alveolar-arterial oxgen difference, AST: aspartate aminotransferase, ALT: alanine aminotransferase 


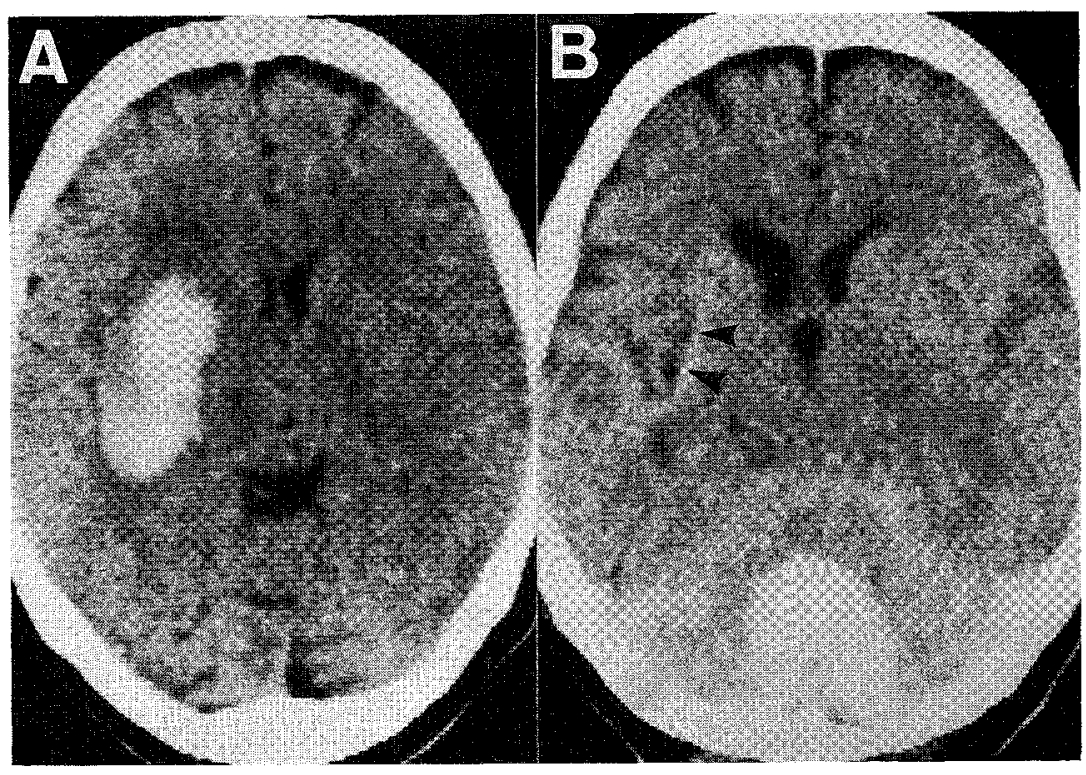

Fig. 2. Brain computed tomography showing left putaminal hemorrhage (A: November 5,1984 ), and showing fresh cerebellar hemorrhage and old putaminal hemorrhage (arrow heads) (B: February 5, 1990).

on brain computed tomography (Fig. 2-A). For the prevention of cerebral edema and tentrial herniation, $200 \mathrm{ml}$ of $10 \%$ glycerol was infused intravenously every six hours. Three days after the onset of this episode, severe pulmonary congestion was found and a subsequent

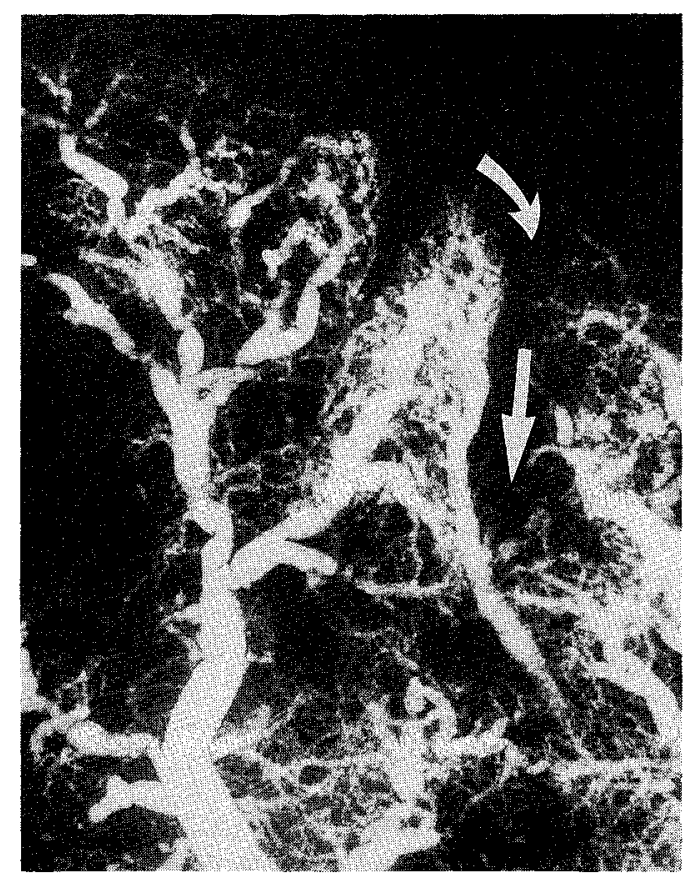

Fig. 3. Radiographic imaging of the lung. Barium solution with $5 \%$ gelatin was injected into the pulmonary artery immediately after death. The peripheral branches of pulmonary arteries are tortuously dilated. Note the carly draining of pulmonary veins through numerous dilated pulmonary capillaries (arrows). total dose of $800 \mathrm{ml}$ of venesection was administered. The patient's hemoglobin concentration was reduced to $163 \mathrm{~g} / \mathrm{l}$ and the findings of her congestive heart failure were improved.

Two months later, she was discharged from the hospital. During the subsequent 5 years, severe hypoxemia continued and her hemoglobin values again became gradually increased and reached $227 \mathrm{~g} / 1$ on November 17, 1989. On February 5, 1990, she complained of trunkal ataxia with severe headache, nausea, and vomiting. Computed tomography taken 6 hours after the initial

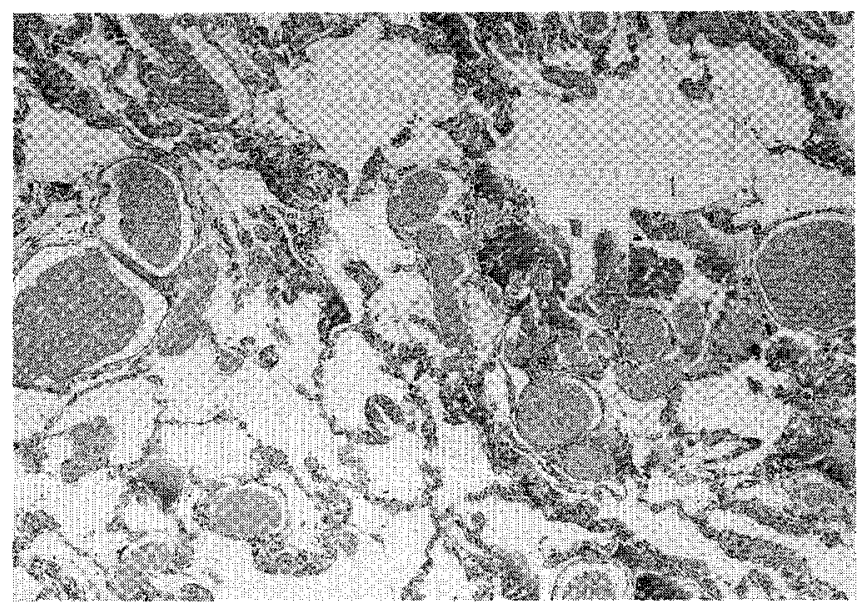

Fig. 4. Histological section of right lower lobe of the lung. The lung has been perfused with barium containing $5 \%$ gelatin. Note the markedly dilated septal vessels filled with bariumgelatin suspension. These are scen close to seemingly normal alveoli. Average minimal luminal diameter of largest vessels is 100 to $150 \mu \mathrm{m}$.

(Hematoxylin eosin, original magnification $\times 40$ ). 
symptom disclosed not only old putaminal hemorrhage but also a fresh cerebellar hemorrhage (Fig. 2-B). She died as a result of the progression of these attacks and multiple organ failure 9 days later.

Postmortem examination revealed macronodular cirrhosis, fresh cerebellar hemorrhage, and old putaminal hemorrhage. There was no intracranial arteriovenous malformation. For further evaluation of the lungs in hepatopulmonary syndrome, a barium solution with 5\% gelatin was injected into the pulmonary artery using a previously described method (2). In radiographic imaging, the peripheral branches of her pulmonary arteries were tortuously dilated and the early draining of the pulmonary veins through numerous dilated capillaries was also found (Fig. 3). Microscopically, there were numerous thin-walled vessels noted within the lungs. These were seen close to seemingly normal alveoli (Fig. 4). No arteriovenous malformations were evident in either lung, either histologically or angiographically.

\section{Discussion}

In the present case, severe hypoxemia without hypercapnea was noted. The pulmonary functions were within normal limits except for the diffusion limitation. Intravenously injected ${ }^{99} \mathrm{~m}$ Tc-macroaggregated albumin particles passed through the pulmonary vasculature into the systemic circulation and lodged in endoorgan capillary beds, such as in the kidneys, spleen, and brain. The postmortem examination confirmed a marked dilatation of the pulmonary alveolar capillaries prominent in the lower zone of the lungs. These findings are consistent with those of hepatopulmonary syndrome $(1-7,9)$.

Patients with hepatopulmonary syndrome often have an accompanying mild to moderate erythrocytosis to compensate for severe hypoxemia $(6,7)$. In the present case, erythrocytosis was progressive, and two episodes of intracranial hemorrhage occurred during the followup period. Liver cirrhosis is known to a possible causal factor of spontaneous intracerebral hemorrhage (11). However, since the two hemorrhagic episodes in the present patient occurred during similar hemoglobin concentrations, it is highly likely that the condition of marked erythrocytosis was the primary factor in the two hemorrhagic accidents.

The occurrence of intracranial hemorrhage is known to be common among patients with polycythemia vera (12). The increased risk of vascular accidents in these patients is thought to be due to the increased blood viscosity, physical distension of the vascular bed, and platelet and plasma factor abnormalities (12). The marked erythrocytosis in the present case may also represent conditions in the intracranial vascular bed, similar to those found in polycythemia vera. To our knowledge, complication of a fatal intracranial hemorrhage has not been reported in a patient with hepato- pulmonary syndrome.

In patients with hepatopulmonary syndrome, abnormal dilatation of pulmonary capillaries, which is the major cause of hypoxemia $(1,3,4)$, is apparently a functional and reversible condition $(13,14)$. Various vasoactive modulators have been postulated as the etiologic factors (4). An excess production of various vasoactive substances, such as prostaglandins, angiotensin II, and human atrial natriuretic polypeptide, has been noted in patients with cirrhosis of the liver (15). These vasoactive substances can also influence the pulmonary vascular tone and gas exchange (16). Therefore, some of these substances may contribute to the dilatation of pulmonary vascular systems. Indomethacin and octreotide seem to have some effects on pulmonary gas exchange in these patients $(4,17,18)$. However, the precise factors and mechanisms are still unknown to date, and there is no established treatment for severe hypoxemia.

We believe that containment of secondary erythrocytosis is important to prevent fatal intracranial hemorrhage in patients with hepatopulmonary syndrome. Prophylactic venesection and/or supplemental continuous oxygenation should be considered. More recently, resolution of hypoxemia has been reported following orthotodic liver transplantation in a patient with hepatopulmonary syndrome (13). Although liver transplantation for patients with this syndrome is still controversial $(4,5)$, this therapy may be one of the effective treatments.

\section{References}

1) Edell ES, Cortese DA, Krowka MJ, Rehder K. Severe hypoxemia and liver disease. Am Rev Respir Dis 140: 1631, 1989.

2) Davis HH, Schwartz DJ, Lefrak SS, Susman N, Schainker BA. Alveolar-capillary oxygen disequilibrium in hepatic cirrhosis. Chest 73: 507, 1978.

3) Shijo H, Sasaki H, Shimizu M, Okumura M, Sakata H. Marked hypoxia associated with liver cirhosis: Clinicopathological study on hepatopulmonary syndrome. Kanzo 32: 817, 1991 (in Japanese).

4) Krowka MJ. Hepatopulmonary syndrome: An evolving perspective in the era of liver transplantation. Hepatology 11: $138,1990$.

5) Agusti AGN, Roca J, Bosch J, Rodriguez-Roisin R. The lung in patients with cirrhosis. J Hepatol 10: 251, 1990.

6) Shijo H, Hisano S, Aoyama S, Shimizu M, Sakaguchi S, Okumura M. A case report: Liver cirrhosis associated with marked hypoxemia and sccondary crythrocytosis. Kanzo 29: 389, 1988 (in Japanese).

7) Hutchinson DCS, Sapru RP, Sumerling MD, Donaldson GWK, Richmond J. Cirrhosis, cyanosis and polycythemia: Multiple pulmonary anastomoses. Am J Med 45: 139, 1968.

8) Chiang ST. A nomogram for venous shunt (QS/QT) calculation. Thorax 23: 563, 1968 .

9) Shijo H, Hisano S, Sasaki $\mathrm{H}$, et al. Detection of pulmonary teleangiectasia using dynamic pulmonary perfusion imaging in patients with liver cirrhosis. Clin Nucl Med 14: 179, 1989.

10) Caldwell PRB, Fritts HW, Cournand A. Oxyhemoglobin dissociation curve in liver disease. J Appl Physiol 20: 316, 1965.

11) Niijima $H$, Suzuki J, Yomematsu T, Otsuki T. Spontaneous 


\section{Shijo et al}

intracerebral hemorrbage and liver dysfunction. Stroke 19: $852,1988$.

12) Chievitz E, Thiede T. Complications and causes of death in polycythemia vera. Acta Med Scand 172: 513, 1962.

13) Stoller JK, Moodie D, Schiavone WA, et al. Reduction of intrapulmonary shunt and resolution of digital clubbing associated with primary biliary cirrhosis after liver transplantation. Hepatology 11: 54, 1990.

14) Shijo $\mathrm{H}$, Nakayama $\mathrm{K}$, Sasaki $\mathrm{H}$, et al. Reversibility of pulmonary teleangiectasia in liver cirrhosis evidenced by serial dynamic pulmonary perfusion imaging. Clin Nucl Med 14: 909, 1989.

15) Shaw-Stiffel T, Campbell PJ, Sole MJ, et al. Renal prostaglandin $\mathrm{E}_{2}$ and other vasoactive modulators in refractory hepatic ascites:
Response to peritoneovenous shunting. Gastroenterology 95: 1332, 1988.

16) Jones $K$, Higebottom $T$, Wallwoek J. Pulmonary vasodilator with prostacyclin in primary and secondary pulmonary hypertension. Chest 90: 784. 1989.

17) Shijo H, Sasaki H, Yuh K, Sakaguchi S, Okumura M. Effects of indomethacin on hepatogenic pulmonary angiodysplasia. Chest 99: $1027,1991$.

18) Shijo H, Sasaki H, Miyajima $Y$, Okumura M. Effects of prostaglandin $\mathrm{F}_{2 \alpha}$ and indomethacin on pulmonary hemodynamics and gas exchange in hepatogenic pulmonary angiodysplasia. Chest 100: 873, 1991. 